\title{
Quality of diet of working college students
}

\author{
Bartira Gorgulho $^{\mathrm{a}}$, Dirce Maria Lobo Marchioni ${ }^{\mathrm{a}^{* *}}$, Adriana Balian da Conceição ${ }^{\mathrm{b}}$, Josiane \\ Steluti $^{\mathrm{a}}$, Marina Hurga Mussi ${ }^{\mathrm{b}}$, Roberta Nagai-Manelli ${ }^{\mathrm{c}}$, Liliane Reis Teixeira ${ }^{\mathrm{d}}$, Andréa \\ Aparecida da Luz ${ }^{\mathrm{b}}$, Frida Marina Fischer ${ }^{\mathrm{b}}$ \\ ${ }^{a}$ Department of Nutrition, University of Sao Paulo, School of Public Health, Avenue Dr Arnaldo 715, \\ São Paulo,SP,Brazil. \\ ${ }^{b}$ Department of Environmental Health, University of São Paulo, School of Public Health, Av. Dr Arnaldo \\ 715, São Paulo,SP,Brazil. \\ ${ }^{c}$ Stress Research Institute, Stockholm University, Stockholm, Sweden \\ ${ }^{d}$ FIOCRUZ, CEHST/National School of Public Health Sergio Arouca, Rio de Janeiro, RJ
}

\begin{abstract}
Considering the scarcity of studies with young workers and the role of diet in the prevention of chronic diseases, the objective of the study was to assess the quality of diet of working college students. The present study investigated 43 university students, aged between 18 and 25 years old who had systematically being involved in a working activity in the past 6 months, paid or unpaid, at least 6 hours daily, five days a week. Dietary intake measured by seven dietary records covering every day of the week was used to calculate the Brazilian Healthy Eating Index Revised (B-HEIR). It was observed a low B-HEIR score $(53.43, \pm 7.81)$ indicating a risk of a poor quality of diet, with high intake of sodium and sugar and low consumption of fruits and whole grains. This poor quality of diet can result in an inadequate nutritional status that may increase the risk of obesity and chronic diseases.
\end{abstract}

Keywords: diet, workers, young adults.

\section{Introduction}

The workplace is a manageable communitybased setting for ensuring proper nutrition. However, studies have shown that the diets among workers served in these places are far from presenting healthy characteristics. Great emphasis is placed on preparations that are palatable to employees; these present high energy density and are usually cheaper to prepare [2,3]. Due to the double take (study and work) working students often experienced fatigue and excessive sleepiness, and do not have enough time and will to follow healthy lifestyles. Sedentariness and reduced sleep are commonly observed in this population [10]. One usual complaint is not having enough time to eat right $[1,10]$.

Valid and reliable measures are required to assess effect from the environment on individual dietary behavior, and form the foundation of research that may inform policies relating to obesity. Although many methods of measuring the food environment exist, this area of research is still relatively new. Dietary patterns have emerged as an alternative or adjunct to the traditional approach of using single nutrients or food groups as exposures for examining associations between diet and health [4]. Several dietary quality scores have been used to classify and describe dietary patterns, such as the Healthy Eating Index (HEI) [5]. However, it has been recognized that application of the HEI in other countries requires certain adaptation [5,11]. Previdelli and colleagues (2010) proposed and assessed the applicability of an HEI version adapted and revised for the Brazilian population (B-HEIR) [9]. Considering the scarcity of studies with young workers and the role of diet in the prevention of chronic diseases, the objective of the study was assess the quality of diet of young working college students. 


\section{Method}

The present study assessed the quality of diet of 43 university students (49\% males) aged between 18 and 25 who had a systematic work activity, paid or unpaid, at least 6 hours daily, five days a week, in the past six months. Data collection took place during the first half of 2008. The participants were working college students attending evening classes, at a public university in São Paulo, Brazil. They received explanations about the objectives of the study and signed a digital consent form.

Anthropometric measurements were checked by the dietitian weight and height. Body weight was assessed using a digital scale $\left(\right.$ Tanita $^{\circledR}$ ) and height was measured using a portable stadiometer. The measurements were used to compute body mass index (BMI; calculated as $\mathrm{kg} / \mathrm{m} 2$ ). The individuals were classified as normal weight (BMI $<25 \mathrm{~kg} / \mathrm{m} 2)$, overweight (25 kg/m2 $<$ BMI $<30 \mathrm{~kg} / \mathrm{m} 2)$, obese I $(30 \mathrm{~kg} / \mathrm{m} 2<\mathrm{BMI}<35 \mathrm{~kg} / \mathrm{m} 2)$ and obese II $(\mathrm{BMI} \geq 35 \mathrm{~kg} / \mathrm{m} 2)$.

Dietary intake measured by seven dietary records covering every day of the week was used to calculate the Brazilian Healthy Eating Index Revised (B-HEIR) [9].

The components were primarily based on Dietary Guidelines for Brazilians (2006) and expressed on a density basis (1000kcal/g). Intakes at the level of the standard or more were assigned the maximum number of total points: 5 points (Total Grains; Whole Grains; Dark-Green and Orange Vegetables and Beans (GOV-B); Total Vegetables; Total Fruit and Whole Fruit); 10 points (Dairy Products; Meat and Beans;
Oils; Saturated Fat; and Sodium) and 20 points for SoFAAS (total calories from solid fat, alcohol and added sugar).

The statistical analysis used STATA software.

The study was approved by the Ethics Committee of the School of Public Health, University of São Paulo, accredited by the National Board of Health.

\section{Results}

The nutritional status of the students is in the figure 1 .

The average score of the B-HEIR and the scores of each component are in the table 1.

\section{Discussion}

It was observed a low B-HEIR score, indicating a risk to a poor quality of diet, with high intake of sodium and sugar and low consumption of fruits and whole grains. This poor diet can result in an inadequate nutritional status that may increase the risk of obesity and chronic diseases. This was confirmed by the nutritional status of the students: $31.8 \%$ and $47.6 \%$ respectively of females and males were overweight; and $4.6 \%$ and $4.8 \%$ respectively of females and males were obese.

Humans are essentially "hardwired" preferring foods that are high in sugar and fat and, hence, rich in energy. On the other hand, humans are not predisposed to engage in physical activity for the purpose of being physically active per se. Particularly working students are hampered by lack of time [10].

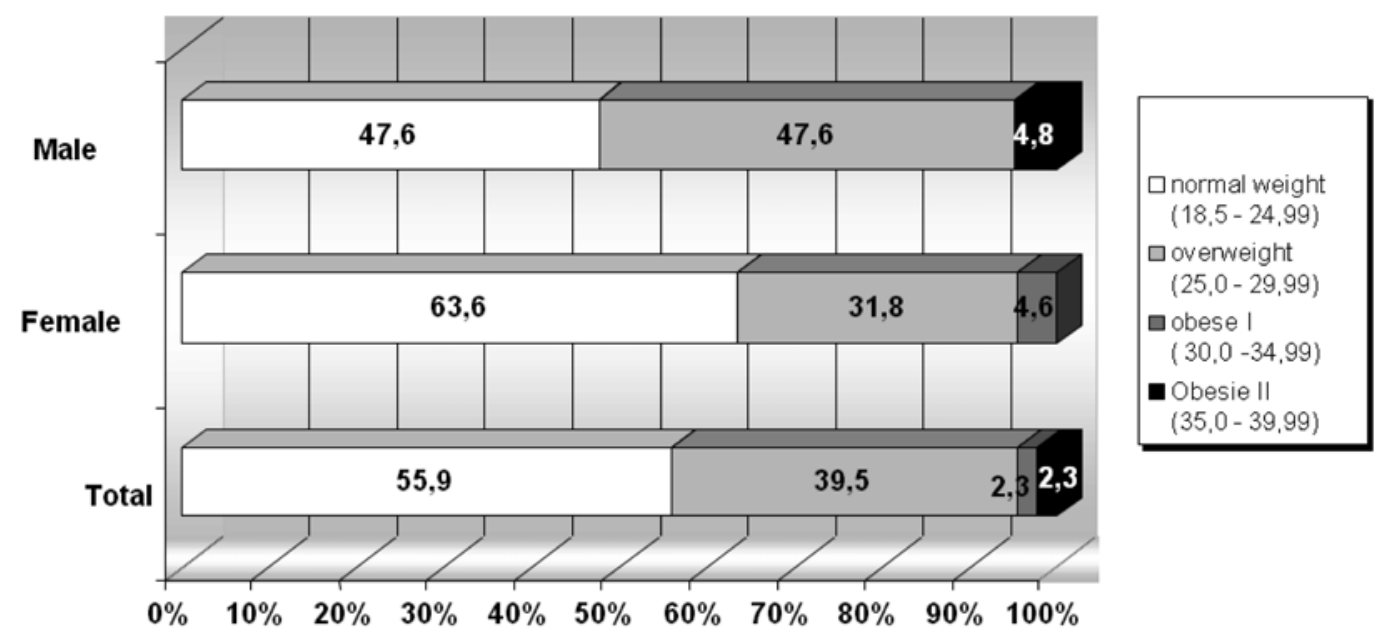

Figure 1. The nutritional status of the students. São Paulo, SP. 2008 
Table1. Score of B-HEIR of working college students. São Paulo, SP. 2008.

\begin{tabular}{|c|c|c|c|c|c|c|}
\hline & \multicolumn{4}{|c|}{ Final score } & \multicolumn{2}{|c|}{ Reference score } \\
\hline & mean & sd & minimum & maximum & minimum & maximum \\
\hline Total fruit & 2,26 & 2,07 & 0,00 & 5,00 & 0,00 & 5,00 \\
\hline Whole fruit & 0,02 & 0,15 & 0,00 & 0,69 & 0,00 & 5,00 \\
\hline Total vegetables & 5,00 & 0,00 & 5,00 & 5,00 & 0,00 & 5,00 \\
\hline GOV-B & 4,79 & 0,55 & 2,59 & 5,00 & 0,00 & 5,00 \\
\hline Total grains & 4,76 & 0,47 & 3,27 & 5,00 & 0,00 & 5,00 \\
\hline Whole grains & 0,29 & 0,30 & 0,00 & 0,89 & 0,00 & 5,00 \\
\hline Dairy products & 6,63 & 2,16 & 1,55 & 10,00 & 0,00 & 10,00 \\
\hline Meat and beans & 9,95 & 0,31 & 7,96 & 10,00 & 0,00 & 10,00 \\
\hline Oils & 10,00 & 0,00 & 10,00 & 10,00 & 0,00 & 10,00 \\
\hline Satured fat & 4,23 & 2,83 & 0,00 & 9,55 & 0,00 & 10,00 \\
\hline Sodium & 0,01 & 0,08 & 0,00 & 0,54 & 0,00 & 10,00 \\
\hline SoFAAS & 5,05 & 4,31 & 0,00 & 13,51 & 0,00 & 20,00 \\
\hline B-HEIR & 53,43 & 7,81 & 39,68 & 70,84 & 0,00 & 100,00 \\
\hline
\end{tabular}

Lowe (2003) reviewed the evidence regarding factors that affect human food intake and concluded that it was essentially unfeasible for humans to self-regulate their food intake under current environmental circumstances, orat least, without first applying substantial cognitive control [6]. However, a substantial body of behavioral research data suggested that

beneficial changes are not achieved and maintained without concomitant changes in policies and environments that support them[8].

We live in what has been called an obesogenic environment. This can be defined as the sum of influences (including our surroundings, opportunities, and/or conditions of life) that promote obesity among individuals and populations. For this reason, researchers are developing measurements of the food environment to investigate their effects on individual diets, aiming to reduce the prevalence of obesity through targeted interventions. Thus, our study that evaluated the quality of diet of working college students might help to drive forward other nutritional interventions that could take into account, besides the individual behavior, the surrounding environment and the influence of work/study activities to the nutrition habits.

\section{Acknowledgments}

Financial support was provided by: FAPESP (grants 2007/04648-4;2008/03191-3; 2009/057376); CNPq (grants n ${ }^{\circ} .500782 / 2008-3 ; 01292 / 2008$ -

0); CAPES; CNPq/PIBIC (2007- 2008).

\section{References}

[1] F.M.Fischer,D.C.Oliveira,L.R.Teixeira, M.C.T.V.Teixeira, M.A.Amaral. Efeitos do trabalho sobre a saúde dos adolescentes. Ciência e Saúde Coletiva, 8 (2003),984-2003.

[2] M.C. Martinez, M.R.D.O. Latorre. Fatores de risco para hipertensão arterial e diabete melito em trabalhadores de empresas metalúrgica e siderúrgica. Arq Bras Cardiol. 87 (2006), 471-92.

[3] M.F.D. Matos, N.A.S. Silva, A.J.M. Pimenta, A.J.L.A. Cunha. Prevalência dos fatores de risco para doença cardiovascular em funcionários do Centro de Pesquisas da Petrobrás. Arq Bras Cardiol. 82 (2004), 1-4.

[4] A.K. Kant. Dietary patterns and health outcomes. J Am Diet Assoc. 104 (2004), 615-635.

[5] E.T. Kennedy, J. Ohls, S Carlson., K. Fleming. The Healthy Eating Index: design and applications. J Am Diet Assoc. 95 (1995), 11031108.

[6] M.R. Lowe. Self-regulation of energy intake in the prevention and treatment of obesity: is it feasible?. Obes Res. 11 (2003), 44S-59.

[7] L.A. Lytle. Measuring the food environment: state of science. Am J Prev Med. 36 (2009) 134144.

[8] Ministério da Saúde. Guia alimentar para a população brasileira. Promovendo a alimentação 
saudável. Normas e manuais técnicos. Brasília (2006).

[9] N.A. Previdelli, M. Lipi, M.A. Castro, D.M.L. Marchioni. Dietary Quality and associated factors among factory workers in the metropolitan region of São Paulo, Brazil. JADA. 110 (2010), 786790.

[10] L.R. Teixeira, F.M.Fischer, R. Nagai, S.L. Turte.
Teen at work: the burden of double shift on daily activities, Chronobiol Int 21 (2004), 845-858.

[11] US Department of Agriculture and Departments of Agriculture and Health and Human Services. Nutrition and Your Health Dietary Guidelines for Americans. 4th ed. Washington, DC: Home and Garden Bulletin no. 232 (1995). 